\title{
HAZARD PROPORTIONAL REGRESSION STUDY TO DETERMINE STROKE RISK FACTORS USING BRESLOW METHOD
}

\author{
Sudarno, Eri Setiani \\ Department of Statistics, Faculty of Science and Mathematics, Diponegoro University \\ e-mail: dsghani@gmail.com
}

DOI: 10.14710/medstat.12.2.200-213

\section{Article Info:}

Received: 12 September 2019

Accepted: 21 December 2019

Available Online: 30 December 2019

Keywords:

Breslow method, Cox proportional hazard regression, Schoenfeld residual, Stroke

\begin{abstract}
Cox proportional hazard regression is a regression model that is often used in survival analysis. Survival analysis is phrase used to describe analysis of data in the form of times from a well-defined time origin until occurrence of some particular be death. In analysis survival sometimes ties are found, namely there are two or more individual that have together event. The objectives of this research are applied Cox proportional hazard regression on ties event using Breslow method and determine factors that affect survival of stroke patients in Tugurejo Hospital Semarang. The response variable is length of stay at hospital, and the predictors are gender, age, type of stroke, history of hypertension, systolic blood pressure, diastolic blood pressure, blood sugar levels, and body mass index. The factors cause stroke disease by significant are type of stroke, history of hypertension, systolic blood pressure, diastolic blood pressure, and blood sugar level. By the survivorship function that the patients have been looked after at hospital greater than 20 days, they have probability of healthy be little even go to death. A person in order to be healthy must notice and prevent some factors cause disease.
\end{abstract}

\section{INTRODUCTION}

Survival analysis is a method to describe data analysis in the form of time, that is, from the early detection until the outbreak of certain event (Collet, 2015). According to Kleinbaum and Klein (2005), the intended time is time in units of years, months, weeks, or days from the beginning of the individual's observation until the occurrence of desired event. Conversely, the related event or incident is death, recurrence of disease after treatment, recovery or experience determined by the researcher for the benefit of the individual under study. Survival analysis applies the concept of censorship. Censorship occurs when events have information about the life time of individuals, but do not tell for certain the time of death. Thus, the data is said to be censored (Lee and Wang, 2013).

To analyze survival data, we can use the survival regression method to find the relationship between the independent variable (predictor) and life time as the dependent 
variable (response). This study used the semiparametric regression model of Cox proportional hazard regression. This is because the Cox proportional hazard regression model does not require assumptions about the distribution of survival time (Lee and Wang, 2003). In survival analysis, common events are often called ties, which are defined as a situation when two or more individuals experience an event at the same time. Such joint events can cause problems in the estimation of parameters related to the determination of members of the set of risks. Because the estimation results of the parameters can be biased, it can be solved using the weight similarity method (Xin, et al., 2017).

Several previous studies on the Cox proportional hazard regression analysis include the one conducted by Sudana, et al. (2013) pinpointing that the factors influencing the length of time to look for work is residence, sex and marital status. Marisa, et al. (2016) explained that the length of the study was influenced by the performance index in semester 2, 3 and 4 and the independent admission. Whereas Dewi, et al. (2016) revealed that the patient's diet of diabetes mellitus was influenced by gender, blood sugar level status, and concomitant diseases. Also Faruk (2017) articulated that the birth interval of the first child is influenced by age, parental education and economic level.

This study used Cox proportional hazard regression with the Breslow approach to look for a significant effect of the predictors consisting of patient status, sex, age, type of stroke, hypertension record, systolic blood pressure, diastolic blood pressure, blood sugar level at a time, and index body mass response to the variable response time to survival. In addition, the survivorship function was used to predict the relationship between time of illness and the chance of recovery. The Breslow method assumed that the size of the set of risks in a joint event is the same (Xin, et al., 2017). The sample of patients in this study were stroke patients at the Regional General Hospital, RSUD Tugurejo, Semarang City. This study is expected to provide a model that can provide information of significant factors on the causes of stroke. Knowing the risk factors of stroke, a person can prevent their occurrence, receive good medical treatment, stay healthier and have a long life.

\section{LITERATURE REVIEW}

\subsection{Cox Proportional Hazard Regression and Survivorship Function}

There are three conditions to determine survival time, namely the clear definition of origin of time, the determination of time scale, and the clear meaning of failure such as a recurrence or recovery of a disease (Cox and Oakes, 1998). According to Collet (2015), the value of the independent variable in the proportional hazard model is represented by vector $\mathbf{x}$, where $\mathbf{x}=\left(x_{1}, x_{2}, \ldots, x_{p}\right)^{\prime}$. The hazard function $h_{i}(t)$ for $\mathrm{i}$-th individuals is written with

$$
h_{i}\left(t \mid \mathbf{x}_{i}\right)=\psi\left(\mathbf{x}_{i}\right) h_{0}(t)
$$

where $\psi\left(\mathbf{x}_{i}\right)$ is the function of the vector value of the independent variable for the $\mathrm{i}$-th individual:

$$
\psi\left(\mathbf{x}_{i}\right)=\exp \left(b_{1} x_{1 i}+b_{2} x_{2 i}+\cdots+b_{p} x_{p i}\right)
$$

In brief, the proportional hazard model can be written as

$$
h_{i}\left(t \mid \mathbf{x}_{i}\right)=\exp \left(\mathbf{b}^{\prime} \mathbf{x}_{i}\right) h_{0}(t)
$$

where $h_{i}\left(t \mid \mathbf{x}_{i}\right)$ : i-th individual failure function 


$$
\begin{aligned}
h_{0}(t) \quad: & \text { basic failure function } \\
\mathbf{b}^{\prime} & : \text { coefficient vector of the independent variable }\left(b_{1}, b_{2}, \ldots, b_{p}\right), \\
& \text { measuring } 1 \times \mathrm{p} . \\
\mathbf{x}_{i} & : \text { independent variable value vector }\left(x_{i 1}, x_{i 2}, \ldots, x_{i p}\right)^{\prime}, \\
& \text { measuring } \mathrm{p} \times 1 \text { with } i=1,2, \ldots, n .
\end{aligned}
$$

By considering the nature and proportional conditions or ratios, equation (3) is equivalent to

$$
S(t \mid \mathbf{x})=\left[S_{0}(t)\right]^{\exp \left(\mathbf{b}^{\prime} \mathbf{x}\right)}
$$

known as the survivorship function, where $S_{0}(t)$ is a basic survey function that is timedependent $t$. In addition, in natural logarithms equation (3) is expressed as

$$
\log \frac{h_{i}\left(t \mid \mathbf{x}_{i}\right)}{h_{0}(t)}=\mathbf{b}^{\prime} \mathbf{x}_{i}
$$

which is called a function of the hazard ratio or relative risk. Relative risk is a function of multiple linear regression without constants or regression functions through a central point. The risk function is independent of time $\mathrm{t}$ (Lee et al., 2013).

\subsection{Assumption of Cox Proportional Hazard Regression}

According to Lee and Wang (2013) the Cox proportional hazard regression model does not require information about the distribution that underlies the survival time. The proportional hazard function in the model can take any form of distribution, but it should fulfil an assumption, namely the proportional hazard assumption. The proportional hazard assumption states that the independent variable (predictor) must be independent or independent of time. Testing of the proportional hazard assumption through the Goodness of Fit approach is conducted through residual Schoenfeld. According to Kleinbaum and Klein (2005), the steps for testing the proportional hazard assumption are as follows:

1. Constructing a proportional Cox hazard and residual Schoenfeld model for each individual on each independent variable.

2. Determining variables that state rank of the survival time.

3. Testing the correlation between residual Schoenfeld variables with survival time in step 2. According to Nurfain and Purnami (2017) statistical testing for the i-individual independent variable uses the following hypothesis.

Hypothesis:

$\mathrm{H}_{0}$ : there is no correlation between rank variable and residual Schoenfeld values of each variable (proportional hazard assumption fulfilled).

$\mathrm{H}_{1}$ : there is a correlation between rank variables with the Schoenfeld residual value of each variable (proportional hazard assumption not met).

Significance Level: $\alpha$

Test Statistics:

$$
r_{h}=\frac{\sum_{i=1}^{n}\left(R_{j i}-\bar{R}_{j i}\right)\left(R T_{i}-\overline{R T_{i}}\right)}{\sqrt{\sum_{i=1}^{n}\left(R_{j i}-\bar{R}_{j i}\right)^{2}} \sqrt{\sum_{i=1}^{n}\left(R T_{i}-\overline{R T_{i}}\right)^{2}}}
$$


where

$\mathrm{r}_{\mathrm{h}} \quad$ : hazard correlation coefficient

$R_{j t}$ : Schoenfeld residual for each $\mathrm{j}$-th independent variable where $j=1,2, \ldots, p$ for i-th individual where $i=1,2, \ldots, n$.

$\mathrm{RT}_{\mathrm{i}}$ : $\mathrm{i}$-th individual survival time.

Rejection Criteria:

$\mathrm{H}_{0}$ is rejected if $\left|r_{h}\right|>r_{n-2, \frac{\alpha}{2}}$ or the value of $-p<\alpha$.

\subsection{Parameter Estimation and Testing}

Survival analysis sometimes contains simultaneous events called ties. Collet (2015), defined ties as conditions when there are two or more individuals experiencing an event of failure at the same time or having the same survival time value. Such simultaneous events can cause problems in the estimation of parameters related to the determination of members of the set of risks. To approach simultaneous events, we used the Breslow method. The Breslow method assumes that the size of the set of risks in ties is the same. Following is the likelihood function for the Breslow method:

$$
L(\mathbf{b})=\prod_{i=1}^{n} \frac{\exp \left(\mathbf{b}^{\prime} \mathbf{s}_{i}\right)}{\left(\sum_{l \in R\left(t_{i}\right)} \exp \left(\mathbf{b}^{\prime} \mathbf{x}_{i}\right)\right)^{d_{i}}}
$$

Where $t_{\mathrm{i}}$ : time of the i-individual event

$\mathbf{s}_{\mathrm{i}} \quad$ : variable vectors of all individuals who died at the time of $t_{\mathrm{i}}$

$R\left(t_{i}\right)$ : risk set of individuals who survive at the time of $t_{\mathrm{i}}$

$\mathbf{x}_{i} \quad$ : variable vectors of individuals who still survive and are elements of $R\left(t_{i}\right)$

$d_{i}$ : the number of simultaneous events at $t_{\mathrm{i}}$

According to Hosmer et al. (2008) testing the significance of parameters can use the likelihood ratio test and the Wald test. This test aims to determine the effect of predictor variables in the model. The likelihood ratio test is used for simultaneous tests, while the Wald test is used for partial tests of parameters.

a. Likelihood Ratio Test

Hypothesis:

$\mathrm{H}_{0}$ : Together the predictors do not affect the model

$\mathrm{H}_{1}$ : at least one predictor affects the model

Significance Level: $\alpha$

Test Statistics:

$$
G=-2[\ln L(0)-\ln L(b)]
$$

where $\ln L(0): \log$ partial likelihood of a model without independent variables.

$\ln L(b): \log$ partial likelihood of the model consisting of $\mathrm{p}$ independent variables. 
Rejection Criteria

$\mathrm{H}_{0}$ is rejected if $G \geq \chi_{p, \alpha}^{2}$ or the value of $-p<\alpha$

b. Wald Test

Hypothesis:

$\mathrm{H}_{0}: \mathrm{j}$-predictor has no effect on survival time

$\mathrm{H}_{1}$ : j-predictor influences survival time, $j=1,2, \ldots, p$

Significance Level: $\alpha$

Test Statistics:

$Z^{2}=\left[\frac{b_{j}}{s e\left(b_{j}\right)}\right]^{2}$

where $\operatorname{se}\left(b_{j}\right)=\sqrt{\operatorname{var}\left(b_{j}\right)}$

Rejection Criteria

$\mathrm{H}_{0}$ is rejected when $Z^{2}>\chi_{1 ; \alpha}^{2}$ or the value of $-p<\alpha$

\subsection{Failure Ratio}

According to Kleinbaum and Klein (2005), the failure ratio is failure for one group of individuals divided by failure for another group of individuals. The two groups of compared individuals were distinguished by the value of the independent variable. The failure ratio is stated in the following formula:

$$
\mathrm{HR}=\exp \left(\sum_{j=1}^{p} x_{i j}{ }^{*}-x_{i j}\right)
$$

where $\quad x_{i j}$ : variable value of $x_{j}$, of $i$-th individual, where $i=1,2, \ldots, n$

$x_{i j}^{*}:$ variable value of $x_{j}^{*}$, the-i-th individual.

According to Allison (2010) the ratio of failure to independent variables in the Cox proportional hazard model which is categorical with dummy variables of 1 and 0 can be interpreted as a comparison of the failure predictors for individuals who are 1 to the failure predictors of individuals who are 0 . While the comparison result of independent quantitative or continuous variable will be more meaningful if the failure ratio is expressed as a percentage.

\subsection{Stroke}

Stroke is a type of non-communicable disease. In medical language stroke is called celebro-vascular accident (CVA). Stroke is defined as a permanent nerve disorder due to disruption of blood circulation to the brain that occurs around 24 hours or more (Lingga, 2013). Based on its trigger, the stroke is divided into two types, namely ischemic stroke and hemorrhagic stroke. Ischemic stroke is a type of stroke that is attributable to blocked blood vessels of the brain by plaque (material consisting of protein, calcium, and fat) which causes the blocked flow of oxygen through the arteries. The hemorrhagic stroke is a type of stroke caused by brain hemorrhage due to rupture of blood vessels in the brain. 
Stroke risk factors are divided into two, namely uncontrolled factors (fixed factors) and controlled factors (non-fixed factors). Uncontrollable factors in the form of genetic factors (race) are age, gender, and history of illness experienced by parents or siblings. While controlled factors are in the form of smoking, alcoholic consumption and sedentary lifestyle (Ministry of Health, Republic of Indonesia, 2014).

\section{RESEARCH METHODS}

\subsection{Type and Source of Data}

This study used secondary data obtained from the medical records of stroke inpatients at the Tugurejo Regency General Hospital, Semarang City from January 2018 to December 2018. Data processing was conducted using SAS software in Allison (2010) and $\mathrm{R}$ in Fox \& Wisberg (2018).

\subsection{Research Variables}

The variables used were length of survival, status, sex, age, type of stroke, hypertension record, systolic blood pressure, diastolic blood pressure, blood sugar levels and body mass index. The study observed 10 variables. The response variable is survival time while the covariate is 9 other variables. Full variable descriptions are listed in the following Table 1.

Table 1 Research Variable

\begin{tabular}{rll}
\hline No & \multicolumn{1}{c}{ Variable } & \multicolumn{1}{c}{ Description } \\
\hline 1 & Survival Time $(\mathrm{T})$ & Length of Treatment of stroke patients (days) \\
2 & Patient Status (Cens) & $0=$ survived patients during treatment, 1= dead \\
& patient \\
3 & Sex $\left(\mathrm{X}_{1}\right)$ & $0=$ female, $1=$ male \\
4 & Age $\left(\mathrm{X}_{2}\right)$ & age (tahun) \\
5 & Type of Stroke $\left(\mathrm{X}_{3}\right)$ & $0=$ ischemic stroke, $1=$ hemorrhagic stroke \\
6 & Hypertension Record $\left(\mathrm{X}_{4}\right)$ & $0=$ non hypertension, $1=$ hypertension \\
7 & Systolic Blood Pressure $\left(\mathrm{X}_{5}\right)$ & $\mathrm{mmHg}$ \\
8 & Diastolic Blood Pressure $\left(\mathrm{X}_{6}\right)$ & $\mathrm{mmHg}$ \\
9 & Blood Sugar Level $\left(\mathrm{X}_{7}\right)$ & $\mathrm{mg} / \mathrm{dl}$ \\
10 & Body Mass Index $\left(\mathrm{X}_{8}\right)$ & $\mathrm{kg} / \mathrm{m}^{2}$ \\
\hline
\end{tabular}

\subsection{Data Analysis}

The analysis covers the following steps:

1. Conducting descriptive analysis,

2. Standardizing the continuous free variables using Z-Score normalization.

3. Cox proportional hazard regression modeling using the Breslow method, by way of

a. Making an initial Cox proportional hazard regression model.

b. Testing the Cox proportional hazard assumption using the Goodness of Fit test.

c. Conducting parameter significance tests consisting of simultaneous tests and partial tests.

d. Forming the final Cox proportional hazard regression model and the best survivorship function.

4. Interpreting the best model of Cox proportional hazard regression that has been formed. 


\section{RESULTS AND DISCUSSION}

The research process and discussion are presented in the following description in the form of tables and explanation.

\subsection{Descriptive Analysis}

Descriptive analysis was used to show the characteristics of stroke patients at Tugurejo Regency Hospital, Semarang City. This study involved 288 patients as sample size with 51 samples or $18 \%$ of the sample was observable or uncensored data and the remaining 237 samples or $82 \%$ were censored data. Descriptive analysis for continuous independent variables is presented in Table 2 .

Table 2 Descriptive Statistics for Continuous Independent Variables

\begin{tabular}{lccc}
\hline \multicolumn{1}{c}{ Variables } & Average & Minimum & Maximum \\
\hline Age & 59 & 25 & 89 \\
Systolic Blood Pressure & 170 & 70 & 257 \\
Diastolic Blood Pressure & 97 & 14 & 174 \\
Blood Sugar Level & 160 & 61 & 957 \\
Body Mass Index & 24.21 & 14.10 & 39 \\
\hline
\end{tabular}

Descriptive analysis for the categorical independent variables are presented in Table 3.

Table 3 Descriptive Statistics for Categorical Independent Variables

\begin{tabular}{llrrr}
\hline \multirow{2}{*}{ Variables } & \multirow{2}{*}{ Category } & \multicolumn{2}{c}{ Status } & \multirow{2}{*}{ Total } \\
\cline { 3 - 4 } & & Uncensored & Censored & \\
\hline \multirow{2}{*}{ Sex } & Female & 20 & 90 & 110 \\
\cline { 2 - 5 } & Male & 31 & 147 & 178 \\
\hline \multirow{2}{*}{ Type of Stroke } & Ischemic & 22 & 197 & 219 \\
\cline { 2 - 5 } & Hemorrhagic & 29 & 40 & 69 \\
\hline \multirow{2}{*}{ Hypertension Record } & No & 14 & 33 & 47 \\
\cline { 2 - 4 } & Yes & 37 & 204 & 241 \\
\hline
\end{tabular}

\subsection{Cox Proportional Hazard Regression Modeling Using the Breslow Method}

\section{Initial Modeling}

Cox proportional hazard regression models are used to determine the effect of predictors on response. This study used the independent variables of gender $\left(\mathrm{X}_{1}\right)$, age $\left(\mathrm{X}_{2}\right)$, type of stroke $\left(\mathrm{X}_{3}\right)$, hypertension record $\left(\mathrm{X}_{4}\right)$, systolic blood pressure $\left(\mathrm{X}_{5}\right)$, diastolic blood pressure $\left(\mathrm{X}_{6}\right)$, blood sugar levels $\left(\mathrm{X}_{7}\right)$ and body mass index $\left(\mathrm{X}_{8}\right)$. The computational process of stroke patients are summarized in Table 4.

If a significant level is taken $\alpha=10 \%$, it can be seen that the non-influential variables are the variables $\mathrm{X}_{1}, \mathrm{X}_{2}$, and $\mathrm{X}_{8}$ while the influential variables are the variables $\mathrm{X}_{3}, \mathrm{X}_{4}, \mathrm{X}_{5}, \mathrm{X}_{6}$, and $\mathrm{X}_{7}$ on the survival time of patients with stroke. Thus, the initial/complete model of Cox proportional hazard regression is

$$
\begin{gathered}
h(t \mid \mathbf{X})=h_{0}(t) \exp \left(-0.135151 X_{1}+0.056161 X_{2}+1.922832 X_{3}-1.379698 X_{4}+\right. \\
0.020028 X_{5}-0.021741 X_{6}+0.001804 X_{7}+0.295581 X_{8}
\end{gathered}
$$


Table 4 Regression Coefficient and Significant Variable

\begin{tabular}{crcrrrr}
\hline Variable & $\begin{array}{c}\text { Regression } \\
\text { Coefficient }\end{array}$ & $\begin{array}{c}\text { Standard } \\
\text { Error }\end{array}$ & $\mathrm{z}$ & $\operatorname{Pr}(>|z|)$ & \multicolumn{2}{c}{$\begin{array}{c}\text { Confidence Interval } \\
\text { 95\% }\end{array}$} \\
& & & & \multicolumn{1}{c}{ Lower } & \multicolumn{1}{c}{ Upper } \\
\hline $\mathrm{X}_{1}$ & -0.135151 & 0.325935 & -0.415 & 0.67839 & 0.46118 & 1.6548 \\
$\mathrm{X}_{2}$ & 0.056161 & 0.301400 & 0.186 & 0.85218 & 0.58592 & 1.9096 \\
$\mathrm{X}_{3}$ & 1.922832 & 0.333843 & 5.760 & $8.43 \mathrm{e}-09$ & 3.55556 & 13.1596 \\
$\mathrm{X}_{4}$ & -1.379698 & 0.519906 & -2.654 & 0.00796 & 0.09084 & 0.6972 \\
$\mathrm{X}_{5}$ & 0.020028 & 0.008333 & 2.403 & 0.01624 & 1.00370 & 1.0370 \\
$\mathrm{X}_{6}$ & -0.021741 & 0.011751 & -1.850 & 0.06429 & 0.95622 & 1.0013 \\
$\mathrm{X}_{7}$ & 0.001804 & 0.001066 & 1.692 & 0.09067 & 0.99971 & 1.0039 \\
$\mathrm{X}_{8}$ & 0.295581 & 0.327960 & 0.901 & 0.36744 & 0.70666 & 2.5558 \\
\hline
\end{tabular}

Testing Hazard Proportional Assumptions

After knowing the initial model, it was followed by testing the proportional hazard assumption. The assumption testing aims to determine whether the predictors affect the survival time of stroke patients. The assumption testing was conducted using residual Schoenfeld.

Hypothesis:

$\mathrm{H}_{0}: \rho=0$ (assumption of proportional hazard is met)

$\mathrm{H}_{1}: \rho \neq 0$ (assumption of proportional hazard is not met)

Given the significance level is $\alpha=0,1$ the obtained test statistic is in the form of a correlation test between the residual Schoenfeld value and the survival time presented in Table 5.

Tabel 5 Hazard Correlation Coefficient and Hypothesis Decision

\begin{tabular}{crrrc}
\hline Variable & $r_{h}$ & Chisq & $p$-value & Decision \\
\hline $\mathrm{X}_{1}$ & 0.13673 & 1.04278 & 0.307 & $\mathrm{H}_{0}$ is accepted \\
$\mathrm{X}_{2}$ & 0.01486 & 0.00984 & 0.921 & $\mathrm{H}_{0}$ is accepted \\
$\mathrm{X}_{3}$ & 0.02611 & 0.03939 & 0.843 & $\mathrm{H}_{0}$ is accepted \\
$\mathrm{X}_{4}$ & 0.02801 & 0.04166 & 0.838 & $\mathrm{H}_{0}$ is accepted \\
$\mathrm{X}_{5}$ & -0.00811 & 0.00398 & 0.950 & $\mathrm{H}_{0}$ is accepted \\
$\mathrm{X}_{6}$ & 0.08893 & 0.42538 & 0.514 & $\mathrm{H}_{0}$ is accepted \\
$\mathrm{X}_{7}$ & -0.07748 & 0.12895 & 0.720 & $\mathrm{H}_{0}$ is accepted \\
$\mathrm{X}_{8}$ & -0.15832 & 1.21781 & 0.270 & $\mathrm{H}_{0}$ is accepted \\
\hline
\end{tabular}

The Product Moment correlation coefficient values for the two-way test, with the sample size of 288 lead to the $r_{286 ; 0.05}=0.195$. Thus, it can be concluded that there is no correlation between the Schoenfeld residual value with survival time. This means that all variables thought to influence the survival time of stroke patients are to meet the proportional hazard assumption.

\section{Parameter Testing}

After the initial Cox proportional hazard model and the proportional hazard assumption are met, the parameters of the model are tested simultaneously and partially using the Likelihood Ratio test and the Wald test. 
a. Testing the Likelihood Ratio

Hypothesis:

$$
\begin{aligned}
\mathrm{H}_{0}: & \beta_{1}=\beta_{2}=\cdots=\beta_{8}=0 \\
& \text { (together the predictors have no effect on response) } \\
\mathrm{H}_{1}: & \text { at least one predictor } \beta_{j} \neq 0, \text { where } j=1,2, \ldots, 8 \\
& \text { (at least one predictor affects the response) }
\end{aligned}
$$

Suppose the significance level is $\alpha=0,1$ the test statistics is

$$
\mathrm{G}=-2[\ln L(0)-\ln L(\hat{\beta})]==-2[-247.5963-(-222.8770)]=49.4386 .
$$

Because the table statistics is $\chi_{8 ; 0.1}^{2}=13.326$ and the value of $\mathrm{G}$ is $=49.4386, \mathrm{H}_{0}$ is rejected. Thus, it can be concluded that there is at least one predictor variable from the model that significantly influences the survival time of stroke patients.

b. Wald Testing

To find out a predictor variable that significantly influences the survival time of stroke patients, a partial test was performed using the Wald test.

Hypothesis:

$\mathrm{H}_{0}: \beta_{j}=0$ (the $\mathrm{j}$-th predictor has no effect on survival time)

$\mathrm{H}_{1}: \beta_{j} \neq 0$, where $j=1,2, \ldots, 8$ (the $\mathrm{j}$-th predictor affects the survival time)

Given the significance level of $\alpha=0.1$ the test statistical equivalents are tabulated in Table 6.

Tabel 6 Wald Test Result

\begin{tabular}{crrrl}
\hline Variable & $\begin{array}{r}\text { Regression } \\
\text { Coefficient }\end{array}$ & $\begin{array}{r}\text { Standard } \\
\text { Error }\end{array}$ & $p$-value & Decision \\
\hline $\mathrm{X}_{1}$ & -0.135151 & 0.325935 & 0.67839 & $\mathrm{H}_{0}$ is accepted \\
$\mathrm{X}_{2}$ & 0.056161 & 0.301400 & 0.85218 & $\mathrm{H}_{0}$ is accepted \\
$\mathrm{X}_{3}$ & 1.922832 & 0.333843 & $8.43 \mathrm{e}-09$ & $\mathrm{H}_{0}$ is rejected \\
$\mathrm{X}_{4}$ & -1.379698 & 0.519906 & 0.00796 & $\mathrm{H}_{0}$ is rejected \\
$\mathrm{X}_{5}$ & 0.020028 & 0.008333 & 0.01624 & $\mathrm{H}_{0}$ is rejected \\
$\mathrm{X}_{6}$ & -0.021741 & 0.011751 & 0.06429 & $\mathrm{H}_{0}$ is rejected \\
$\mathrm{X}_{7}$ & 0.001804 & 0.001066 & 0.09067 & $\mathrm{H}_{0}$ is rejected \\
$\mathrm{X}_{8}$ & 0.295581 & 0.327960 & 0.36744 & $\mathrm{H}_{0}$ is accepted \\
\hline
\end{tabular}

The value of $\chi_{(1 ; 0.05)}^{2}=3.841$, then based on Table 6 , it can be decided that the Cox proportional hazard model with the Breslow method with the variables of type of stroke type $\left(\mathrm{X}_{3}\right)$, hypertension record $\left(\mathrm{X}_{4}\right)$, systolic blood pressure $\left(\mathrm{X}_{5}\right)$, and diastolic blood pressure $\left(\mathrm{X}_{6}\right)$ and blood sugar levels $\left(\mathrm{X}_{7}\right)$ partially is significant towards the model.

Given the insignificant effects of variables to the model, namely the variables of sex $\left(\mathrm{X}_{1}\right)$, age $\left(\mathrm{X}_{2}\right)$ and body mass index $\left(\mathrm{X}_{8}\right)$, the insignificant variables were excluded from the model using backward selection. The exclusion of insignificant variables was conducted one by one based on the order of the largest value of the p-value. There were three excluded independent variables. The backward selection procedure would stop if all the predictors in the model were significant. Then, the Likelihood Ratio test and the 
Wald test were performed for each model. The backward selection resulted in regression models of all significant independent variables. The discussion is presented below.

\subsection{Cox Proportional Hazard Regression Model and the Best Survivorship Function}

Testing the Best Regression Model and Function

The backward selection process led the results tabulated in Table 7, which is the best builder of the Cox proportional hazard regression model.

Tabel 7 Regression Coefficient and The Best Significant Variable

\begin{tabular}{crrrrrr}
\hline \multirow{2}{*}{ Variable } & Regression & Standard & \multirow{2}{*}{$\mathrm{z}$} & $\operatorname{Pr}(>|z|)$ & \multicolumn{2}{c}{ Confidence Interval 95\% } \\
& Coefficient & Error & & & Lower & Upper \\
\hline $\mathrm{X}_{3}$ & 1.930458 & 0.332333 & 5.809 & $6.29 \mathrm{e}-09$ & 3.59339 & 13.2212 \\
$\mathrm{X}_{4}$ & -1.306462 & 0.508903 & -2.567 & 0.0103 & 0.09987 & 0.7342 \\
$\mathrm{X}_{5}$ & 0.019780 & 0.007953 & 2.487 & 0.0129 & 1.00420 & 1.0360 \\
$\mathrm{X}_{6}$ & -0.022032 & 0.010907 & -2.020 & 0.0434 & 0.95752 & 0.9993 \\
$\mathrm{X}_{7}$ & 0.001928 & 0.001015 & 1.898 & 0.0577 & 0.99994 & 1.0039 \\
\hline
\end{tabular}

The next step is to test the parameters simultaneously using the likelihood ratio test and partially using the Wald test.

a. Testing the Likelihood Ratio

Hypothesis:

$$
\mathrm{H}_{0}: \beta_{3}=\cdots=\beta_{6}=\beta_{7}=0
$$

(together, the predictors have no impact on response)

$\mathrm{H}_{1}:$ at least one predictor $\beta_{j} \neq 0$, where $j=3,4, \ldots, 7$

(at least one predictor affects response)

Given the significance level of $\alpha=0,1$ the computational process leads to the testing statistics of

$$
\mathrm{G}=-2[\ln L(0)-\ln L(\hat{\beta})]=-2[-247.5963-(-223.3450)]=48.5026
$$

Thus, the chi-square table obtained a value of $\chi_{5 ; 0.1}^{2}=9.236$, and the value of $\mathrm{G}=$ 48.5026, so that $\mathrm{H}_{0}$ is rejected. This means that there is at least one predictor of the model that significantly influences the survival time of stroke patients.

b. Wald Testing

Hypothesis:

$\mathrm{H}_{0}$ : j-predictor has no effect on survival time

$\mathrm{H}_{1}$ : j-predictor has no effect on survival time , $j=3,4, \ldots, 7$

Given the significance level of $\alpha=10 \%$ the test statistics lead to the result presented in the following Table 8 . 
Table 8 The Best Wald Model Parameter Test Results

\begin{tabular}{crccc}
\hline Variables & $\begin{array}{c}\text { Regression } \\
\text { Coefficient }\end{array}$ & $\begin{array}{c}\text { Standard } \\
\text { Deviation }\end{array}$ & $p$-value & Decision \\
\hline $\mathrm{X}_{3}$ & 1.930458 & 0.332333 & $6.29 \mathrm{e}-09$ & $\mathrm{H}_{0}$ is rejected \\
$\mathrm{X}_{4}$ & -1.064620 & 0.508903 & 0.0103 & $\mathrm{H}_{0}$ is rejected \\
$\mathrm{X}_{5}$ & 0.019780 & 0.007953 & 0.0129 & $\mathrm{H}_{0}$ is rejected \\
$\mathrm{X}_{6}$ & -0.022032 & 0.010907 & 0.0434 & $\mathrm{H}_{0}$ is rejected \\
$\mathrm{X}_{7}$ & 0.001928 & 0.001015 & 0.0577 & $\mathrm{H}_{0}$ is rejected \\
\hline
\end{tabular}

Because all p-values are smaller than the significance level, $\mathrm{H}_{0}$ is rejected. This means that variable type of stroke $\left(\mathrm{X}_{3}\right)$, history of hypertension $\left(\mathrm{X}_{4}\right)$, systolic blood pressure $\left(\mathrm{X}_{5}\right)$, and diastolic blood pressure $\left(\mathrm{X}_{6}\right)$ and blood sugar levels when $\left(\mathrm{X}_{7}\right)$ are partially significant on the model. Because all variables in the model are significant, the best Cox proportional hazard regression model is resulted from the Breslow method, as given below:

$$
h(t \mid \mathbf{X})=h_{0}(t) \exp \left(\begin{array}{l}
1.930458 X_{3}-1.306462 X_{4}+0.019780 X_{5} \\
-0.022032 X_{6}+0.001928 X_{7}
\end{array}\right)
$$

The above Cox proportional hazard regression leads to the best survivorship function, as given below

$$
S(t \mid \mathbf{X})=\left[S_{0}(t)\right]^{\exp \left(\mathbf{b}^{\prime} \mathbf{x}\right)}
$$

where

$$
\exp \left(\mathbf{b}^{\prime} \mathbf{x}\right)=\exp \left(\begin{array}{l}
1.930458 X_{3}-1.306462 X_{4}+0.019780 X_{5} \\
-0.022032 X_{6}+0.001928 X_{7}
\end{array}\right)
$$

If the survivorship function is applied to the data of this study, we get a picture of the relationship between survival time and the chance of survival in Figure 1.

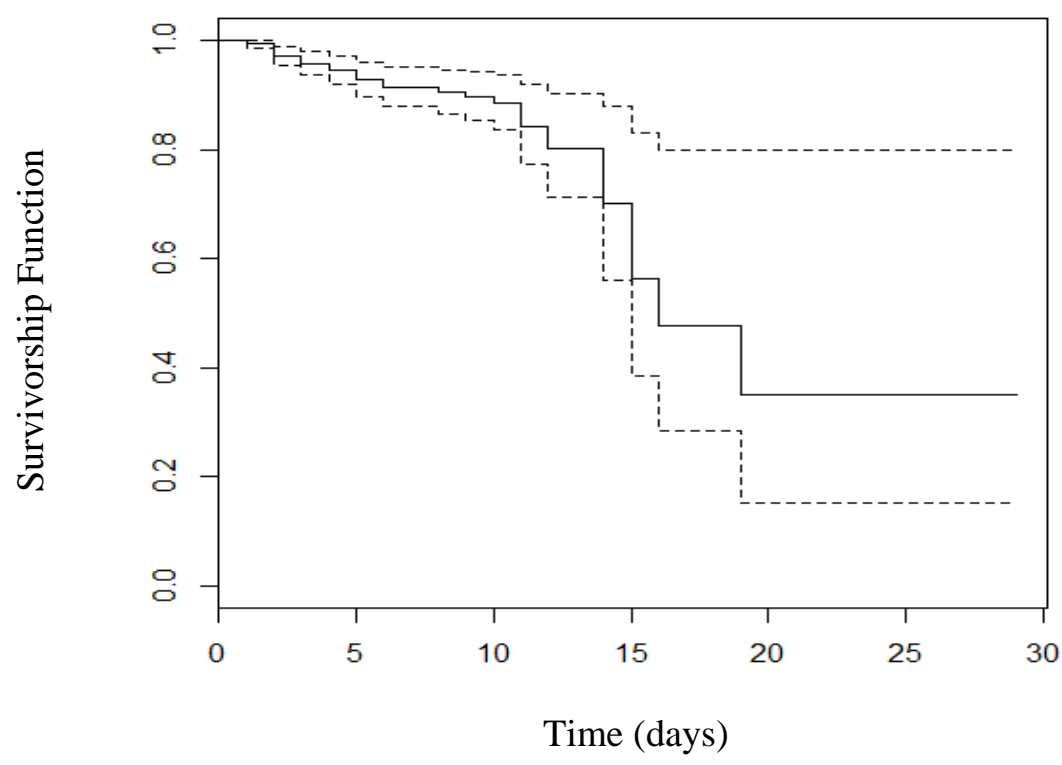

Figure 1 Survivorship Function 
The function of survivorship indicates the classification of healthy opportunities for the duration of illness. The longer a person is sick, the less his chance to survive. During more than 20 days of hospitalization, it was seen that the chance to recover were low and even leading to death.

Table 9 Recovery Opportunities based on the Survivorship Function

\begin{tabular}{ccc}
\hline Time (days) & Recovery Function & Description \\
\hline 5 & 0.98 & High \\
10 & 0.87 & High \\
15 & 0.55 & Medium \\
20 & 0.35 & Low \\
25 & 0.35 & Low \\
\hline
\end{tabular}

The following section discusses the properties of the relative risk function $y=\log \frac{h(t \mid \mathbf{x})}{h_{0}(t)}=\log x$. The properties of the relative risk function are presented in Table 10.

Table 10 Characteristics of Risk Functions

\begin{tabular}{ccc}
\hline $\mathrm{X}$ & $\mathrm{Y}$ & Risks \\
\hline $0<x<1$ & Less than zero & Negative Risk \\
1 & Equals zero & No risk \\
$1<x$ & More than zero & Positive Risk \\
\hline
\end{tabular}

\subsection{Model Interpretation}

The best Cox proportional hazard regression model that has been obtained is

$h(t \mid \mathbf{X})=h_{0}(t) \exp \left(1.930458 X_{3}-1.306462 X_{4}+0.019780 X_{5}-0.022032 X_{6}+0.001928 X_{7}\right)$ In this case, it contains the value of $\exp \left(b_{j}\right), j=3,4,5,6,7$ that indicates the value of the failure ratio of each predictor. The failure ratio is calculated only for variables that affect the survival time of stroke patients. Based on the best model, the failure ratio calculated from the model is presented in Table 11.

The followings are interpretations of the obtained model.

1. Variables affecting the risk factors of stroke for a person are stroke type, hypertension record, systolic blood pressure and diastolic blood pressure, and blood sugar levels.

2. The risk of someone to have an ischemic stroke is 5.893 times higher than someone having a hemorrhagic stroke. Patients affected by hemorrhagic stroke have a 6.893 times chance of survival than patients affected by ischemic stroke.

3. The risk of stroke patients who have no record of hypertension failure to survive is lower 0.729 times than that of stroke patients who have a record of hypertension.

4. An increase in someone's systolic blood pressure results in risk of stroke that is 0.02 times higher than someone with normal systolic blood pressure.

5. A decrease in someone's diastolic blood pressure results in the risk of stroke that is $2.2 \%$ smaller than someone with normal diastolic blood pressure.

6. An increase in blood sugar levels in a person results in a risk factor of stroke that is $0.2 \%$ higher than someone with a normal blood sugar level. 


\section{CONCLUSION}

Based on the study of Cox proportional hazard regression using the Breslow method on the survival data of stroke patients at the Tugurejo Regency Hospital in Semarang it was concluded that Risk Factors of stroke are type of stroke, hypertension record, systolic blood pressure, and diastolic blood pressure. The best Cox proportional hazard regression model is

$$
h(t \mid \mathbf{X})=h_{0}(t) \exp \left(\begin{array}{l}
1.930458 X_{3}-1.306462 X_{4}+0.19780 X_{5} \\
-0.022032 X_{6}+0.001928 X_{7}
\end{array}\right)
$$

The best survivorship function is $S(t \mid \mathbf{X})=\left[S_{0}(t)\right]^{\exp \left(\mathbf{b}^{\prime} \mathbf{x}\right)}$, where

$$
\exp \left(\mathbf{b}^{\prime} \mathbf{x}\right)=\exp \left(\begin{array}{l}
1.930458 X_{3}-1.306462 X_{4}+0.019780 X_{5} \\
-0.022032 X_{6}+0.001928 X_{7}
\end{array}\right)
$$

A person's risk factor for hemorrhagic strokes is lower than that of an ischemic stroke, and his survival is shorter. Someone who has a record of hypertension has a higher risk of stroke than those without. An increase in someone's systolic blood pressure results in a higher failure of life. On this account, a decrease in someone's diastolic blood pressure, the higher the survival of stroke patients.

The longer the period of sickness, the lower the chance of survival. During more than 20 days of hospitalization, it appears that the chances of recovery are low and even leading to death.

\section{REFERENCES}

Allison, P. D. 2010. Survival Analysis Using SAS: A Practical Guide, Second Edition. North Carolina: SAS Institute Inc.

Bain, L. J and Engelhardt, M. 1992. Introduction to Probability and Mathematical Statistics. California: Duxbury press.

Bhandare, S. K. and Jain, Y. K. 2014. Min Max Normalization Based Data Pertubation Method for Privacy Protection. International Journal of Computer \& Communication Technology, Vol. 3, No. 4, pp. 45-50.

Collett, D. 2015. Modelling Survival Data in Medical Research, Third Edition. CRC Press.

Cox, D. R. and Oaks, D. 1998. Analysis of Survival Data. United State of America: Chapman and Hall, Inc.

Dewi, I. A. P. R., Suciptawati, N. L. P, and Tastrawati, N. K. T. 2016. Aplikasi Regresi Cox Proportional Hazard pada Sitasan Pasien Diabetes Melitus, E-Jurnal Matematika, Vol. 7, No. 3, pp. 278-285.

Faruk, A. 2017. Aplikasi Regresi Cox pada Selang Kelahiran Anak Pertama di Provinsi Sumatera Selatan. Jurnal Matematika, Vol. 7, No. 1, pp. 19-29.

Fox, J. and Weisberg, S. 2018. Cox Proportional Hazard Regression for Survival Data in $R$, Third Edition. CA: Thousand Oaks. 
Hosmer, D. W., Lemeshow, S., and May, S. 2008. Applied Survival Analysis: Regression Modelling of Time to Event Data, Second Edition. New Jersey: John Wiley \& Sons, Inc.

Jong, P. D. and Heller, G. Z. 2008. Generalized Linear Models for Insurance Data, United Kingdom: Cambridge University Press.

Kementerian Kesehatan RI. 2014. Info Datin Pusat dan Informasi Kementerian Kesehatan RI, Situasi Kesehatan Jantung. Jakarta.

Kleinbaum, D. G. and Klein, M. 2005. Survival Analysis A Self-Learning Text, Second Edition. London: Springer.

Lee, E. T. and Wang, J. W. 2013. Statsitical Methods for Survival Data Analysis, Fourth Edition, Canada: JohnWiley \& Sons, Inc.

Lingga, L. 2013. All About Stroke Hidup Sebelum dan Pasca Stroke. Jakarta: PT Elex Media Komputindo.

Marisa, Yozza, H. and Mayastri. 2016. Model Regresi Cox Proportional Hazard pada Laju Tamat Mahasiswa Jurusan Matematika Universitas Andalas, Jurnal Matematika UNAND, Vol. VI, No. 1, pp. 33-46.

Nurfain and Purnami S. W. 2017. Analisis Regresi Cox Extended pada Pasien Kusta di Kecamatan Brondong Kabupaten Lamongan. Jurnal Sains dan Seni ITS, Vol. 6, No. 1, pp. 94-100.

Sudana, I. G. A., Suciptawati, N. L. P., and Harini, L. P. I. 2013. Penerapan Regresi Cox Proportional Hazard untuk Menduga faktor-faktor yang Mempengaruhi Lama Mencari Kerja. E-Jurnal Matematika, Vol. 2, No. 3, pp. 7-10.

Xin, X., Harrocks, J., and Darlington, G. A. 2017. Weighting Methods for Ties between Event Times and Covariate Change Times, Journal Communication in StatisticsSimulation and Computation, Vol. 47, Issue 1. 